\title{
The Modulatory Effect of Ischemia and Reperfusion on Arginine Vasopressin-Induced Arterial Reactions
}

\author{
Katarzyna Szadujkis-Szadurska, Bartosz Malinowski, Małgorzata Piotrowska, \\ Grzegorz Grześk, Michał Wiciński, and Marta Gajdus
}

Department of Pharmacology and Therapeutics, Collegium Medicum Nicolaus Copernicus University, Sklodowskiej-Curie Street 9, 85-094 Bydgoszcz, Poland

Correspondence should be addressed to Katarzyna Szadujkis-Szadurska; kataszsz@gmail.com

Received 19 May 2016; Revised 4 July 2016; Accepted 10 July 2016

Academic Editor: Gjumrakch Aliev

Copyright (C) 2016 Katarzyna Szadujkis-Szadurska et al. This is an open access article distributed under the Creative Commons Attribution License, which permits unrestricted use, distribution, and reproduction in any medium, provided the original work is properly cited.

\begin{abstract}
Aim of the Study. The purpose of this study was to investigate the impact of ischemia and reperfusion on the resistance of arteries to AVP (arginine vasopressin), with a particular emphasis on the role of smooth muscle cells in the action of vasopressin receptors and the role of the cGMP-associated signalling pathway. Materials and Methods. Experiment was performed on the perfunded tail arteries from male Wistar rats. The constriction triggered by AVP after 30 minutes of ischemia and 30 and 90 minutes of reperfusion was analysed. Analogous experiments were also carried out in the presence of $8 \mathrm{Br}$-cGMP. Results. Ischemia reduces and reperfusion increases in a time-dependent manner the arterial reaction to AVP. The presence of 8Br-cGMP causes a significant decrease of arterial reactivity under study conditions. Conclusions. Ischemia and reperfusion modulate arterial contraction triggered by AVP. The effect of $8 \mathrm{Br}-\mathrm{cGMP}$ on reactions, induced by AVP after ischemia and reperfusion, indicates that signalling pathway associated with nitric oxide (NO) and cGMP regulates the tension of the vascular smooth muscle cells.
\end{abstract}

\section{Introduction}

Numerous mechanisms regulate arterial blood flow and tissue supply under various conditions. Metabolically active endothelial cells control blood pressure, tension and permeability of vessels, adhesion of inflammatory cells, and platelet aggregation. They are also considered initiators of reperfusion [1]. Diameter of arteries is changed by the endothelium; it results in the blood flow and perfusion changes in response to the vasoconstrictors (i.e., vasopressin) and vasodilators (i.e., nitric oxide) $[2,3]$. Vascular smooth muscle cells are responsible for contractility, growth, and remodelling of blood vessels. Contraction of smooth muscle cells depends on the cytoplasmic calcium ions levels and the extracellular environment [3-6]. NO stimulates guanylate cyclase to produce cGMP, thus leading to relaxation of a vessel.

Blood vessel occlusion leads to ischemia. Cells have energy reserves and an ability to increase the amount of available oxygen, to survive a reduced blood supply. If ischemia lasts for longer period of time, changes in cellular structure occur with a possible necrosis $[4,7]$. Studies indicated an inhibitory effect of ischemia on arterial contractility and shows clear association between NO synthesis and activation of cGMP $[8,9]$.

Hyperaemia is the first response to restored circulation along a given segment. During reperfusion, cellular defence mechanisms are overloaded, which may result in cellular damage [4]. That is why duration of ischemia is so important. The shorter it is, the less severe consequences for cells, tissues, and organs appear. Increased blood flow may cause physical and biochemical disorders in tissues, which may lead to reperfusion cascade, production of intracellular free radicals, release of cytokines, and inflammation development [10].

Therapy involving blockade of the initiators in the reperfusion cascade during the free radicals production is the most effective. That avoids both local and systemic disturbances. After that stage, a further therapy would be aimed at inhibition of neutrophils, granulocytes migration, and production 
of prostaglandins. However, if the inflammatory process and tissue damage are extensive enough to trigger the last part of the cascade, the therapy would be less effective $[4,11]$.

Studies on reperfusion in tail arteries of rats demonstrated increased contractile postreperfusion arterial reactions under an influence of an agonist. It was also mentioned that the reperfusion disturbed balance of the cellular antioxidative system. It was also suggested that the effect of cGMP is not limited to the relaxing action but also modulates reactions triggered by ROS [12].

VP is a nonapeptide of numerous functions. VP is synthesised by hypothalamus and accumulated in the posterior lobe of the pituitary gland. First studies in 1895 demonstrated the hormone's ability to constrict blood vessels, hence its name [13]. However, in 1956 it was demonstrated that VP is the same substance as the antidiuretic hormone (ADH), and both names are still in use as synonyms [14].

VP deficiencies occur in some shock states, but external administration of AVP may alleviate them. Studies have demonstrated that introduction of a low dose of VP in patients with dilated blood vessels reduced the required norepinephrine (noradrenaline) dose, making it applicable in case of septic shock. However, it was also paradoxically demonstrated that VP causes relaxation of some blood vessels which makes the hormone different from other vasoconstrictors [15].

Opinions concerning VP administration in cases of cardiac arrest are contradictory. On one hand, it was observed that VP injection during cardiopulmonary resuscitation directs blood from the skin, muscles, and intestines to the heart and brain, which has a favourable effect on function of those organs after restoration of circulation $[16,17]$. However, the effect may be dangerous for the organism as a whole and hinder relaxation of the heart, whereas its contraction remains unchanged [18]. There were also studies indicating protective effect of VP on rat heart during the organ reperfusion after a long hypoxia [19].

There are also reports suggesting that VP may be secreted directly to the brain through an alternative route, acting as a neurotransmitter responsible for regulation of waterelectrolyte homeostasis and production of cerebrospinal fluid $[1,20]$. VP has also antipyretic properties. Its administration may even lead to hypothermia [21].

Metabotropic receptors Vla are present in large quantities in arterial smooth muscle cells and cause contraction of vessels. Those receptors are also abundant in myocytes, cerebral tissue, the superior cervical ganglion of the sympathetic trunk, the liver, blood cells, and the renal core. Precise role of VP in those tissues is subject to numerous studies all over the world [7, 20, 22, 23].

V1b occurs in the pituitary gland, cells of kidneys, brain, thymus, uterus, the myocardium, and lungs [24]. The V2 receptor is largely responsible for antidiuretic character of VP.

The purpose of this study was to investigate the effect of ischemia and reperfusion on reactions of resistance arteries on AVP, with a particular emphasis on the role of smooth muscle cells in the action of VP receptors, and to determine the role of the CGMP-associated signalling pathway in modulation of arterial reaction to AVP.

\section{Materials and Methods}

Our experiment was performed on isolated and perfused tail arteries collected from male Wistar rats under anaesthesia. Rats weighted 220-270 g.

After removal of surrounding tissues, the proximal section of the artery, approximately $3 \mathrm{~cm}$ long, was cannulated and, with the distal end attached to a $0.5 \mathrm{~g}$ weight, the artery was connected to the perfusion pressure recorder. The specimen was positioned vertically in a $20 \mathrm{~mL}$ container for isolated organs filled with aerated Krebs fluid, at $37^{\circ} \mathrm{C}$ and $\mathrm{pH}$ 7.4.

Ischemia was induced by clamping proximal fragment of the artery for 30 minutes. After that time, the artery was cut. In cases of reperfusion, the clamp was removed 30 minutes later, and the artery was cut free after another 30 or 90 minutes.

Krebs fluid, AVP (Sigma), and 8Br-cGMP (Behringer) were used in the study.

To determine the arterial reactivity to AVP, the study involved initial drawing of the control concentrationresponse curve (CRC), using van Rossum's method of accumulated concentrations [25] modified by Grześk and Szadujkis-Szadurski $[26,27]$. Then, CRC in the presence of $8 \mathrm{Br}$-cGMP was determined. Study agents were administered into the $20 \mathrm{~mL}$ container for isolated organs (extravascularly). Based on individual CRCs, the $\mathrm{EC}_{50}$ value (concentration triggering $50 \%$ of the maximum reaction) and the $\mathrm{pEC}_{50}$ value ( $-\log 10$ of $\mathrm{EC}_{50}$ ) were determined. In our experiments, contraction of the vessel was measured by increased pressure of perfusate in the experimental system, at the fixed flow of the fluid (approximately $1 \mathrm{~mL} / \mathrm{min}$ ).

The statistical analysis involved determination of mean values, standard deviations, and $\mathrm{EC}_{50}$ and $\mathrm{pEC}_{50}$ values. Statistical differences were calculated with the ANOVA test. Statistically significant values were interpreted as $p<0.05$. Calculations were completed using the GraphPad Prism 5 software.

\section{Results}

AVP triggers the increase of perfusion pressure in a concentration-dependent manner. Influenced by 30 -minute ischemia, the CRC is shifted to the right, with a simultaneous reduction of the maximum effect. After 30 and 90 minutes of reperfusion, CRCs are shifted to the left, with a simultaneous rise of the maximum effect, in the reperfusion timedependent manner (Figure 1).

Noted changes of curve positions before and after reperfusion are statistically significant. The determined values $\%$ $\mathrm{Ea} / \mathrm{Em}$ and $\mathrm{EC}_{50}$ for AVP in control conditions, and after ischemia and reperfusion, are presented in the Table 1.

Another series of experiments was carried out in the presence of $0.01 \mathrm{mM} / \mathrm{L}$ of $8 \mathrm{Br}-\mathrm{cGMP}$, in order to check the role of the NO-regulated signalling pathway in AVP-triggered reactions of arteries. After addition of $8 \mathrm{Br}$-cGMP, the CRC drawn for AVP was shifted to the right, with reduction of the maximum effect. After 30 minutes of ischemia, a further shift of the CRC to the right was observed, with reduction of Em. After 30 and 90 minutes of reperfusion with addition of 


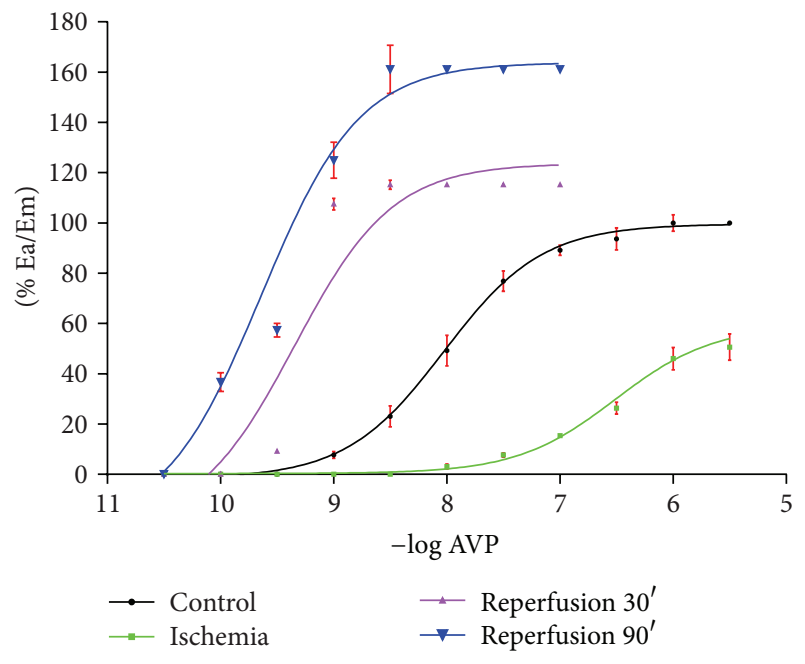

FIGURE 1: The effect (\% Ea/Em) of ischemia $30^{\prime}$ and reperfusion $30^{\prime}$ and $90^{\prime}$ on CRCs for AVP.

TABLE 1: $\% \mathrm{Ea} / \mathrm{Em}, \mathrm{EC}_{50}$, and $\mathrm{pEC}_{50}$ values for AVP determined in control, after ischemia $30^{\prime}$, and after reperfusion $30^{\prime}$ and $90^{\prime}$ conditions.

\begin{tabular}{lccc}
\hline & $\% \mathrm{Ea} / \mathrm{Em}$ & $\mathrm{EC}_{50}$ & $\mathrm{pEC}_{50}$ \\
\hline Control & 100,00 & $9,696 \times 10^{-7}$ & 7,987 \\
Ischemia & 58,92 & $3,355 \times 10^{-6^{*}}$ & $6,526^{\mathrm{a}}$ \\
Reperfusion 30' & 124,50 & $1,535 \times 10^{-9^{* *}}$ & $9,186^{\mathrm{b}}$ \\
Reperfusion 90' & 168,60 & $2,546 \times 10^{-9^{* * *}}$ & $9,406^{\mathrm{c}}$ \\
\hline
\end{tabular}

$\mathrm{EC}_{50}$ control versus $\mathrm{EC}_{50}{ }^{* / * * * * *}, p<0.05 ; \mathrm{pEC}_{50}$ control versus $\mathrm{pEC}_{50}^{\mathrm{a} / \mathrm{b} / \mathrm{c}}, p<0.05 ; \mathrm{pEC}_{50}{ }^{\mathrm{b}}$ versus $\mathrm{pEC}_{50}{ }^{\mathrm{c}}, p=\mathrm{ns}$.

$\% \mathrm{Ea} / \mathrm{Em}: \%$ of maximum reaction.

$\mathrm{EC}_{50}$ : concentration triggering $50 \%$ of the maximum reaction.

$\mathrm{pEC}_{50}:-\log 10$ of $\mathrm{EC}_{50}$.

TABle 2: Values \% $\mathrm{Ea} / \mathrm{Em}, \mathrm{EC}_{50}$, and $\mathrm{pEC}_{50}$ for AVP determined after ischemia and reperfusion in the presence of $8 \mathrm{Br}-\mathrm{cGMP}$.

\begin{tabular}{lccc}
\hline & $\% \mathrm{Ea} / \mathrm{Em}$ & $\mathrm{EC}_{50}$ & $\mathrm{pEC}_{50}$ \\
\hline Control & 100,00 & $9,696 \times 10^{-7}$ & 7,987 \\
AVP + 8Br-cGMP & 79,29 & $3,865 \times 10^{-7^{*}}$ & $7,587^{\mathrm{a}}$ \\
Ischemia + 8Br-cGMP & 21,03 & $3,492 \times 10^{-6^{* *}}$ & $6,543^{\mathrm{b}}$ \\
Reperfusion 30 $+8 \mathrm{Br}-\mathrm{cGMP}$ & 117,70 & $7,583 \times 10^{-8^{\dagger}}$ & $8,880^{\mathrm{c}}$ \\
Reperfusion 90 $+8 \mathrm{Br}$-cGMP & 147,70 & $2,559 \times 10^{-9^{\dagger \dagger}}$ & $9,408^{\mathrm{d}}$ \\
\hline
\end{tabular}

$\mathrm{EC}_{50}$ control versus $\mathrm{EC}_{50}{ }^{* / * * / \dagger / \dagger}, p<0.05 ; \mathrm{pEC}_{50}$ control versus $\mathrm{pEC}_{50}{ }^{\mathrm{b} / \mathrm{c} / \mathrm{d}}, p<0.05 ; \mathrm{pEC}_{50}$ control versus $\mathrm{pEC}_{50}{ }^{\mathrm{a}}, p=\mathrm{ns}$

$\% \mathrm{Ea} / \mathrm{Em}: \%$ of maximum reaction.

$\mathrm{EC}_{50}$ : concentration triggering $50 \%$ of the maximum reaction.

$\mathrm{pEC}_{50}:-\log 10$ of $\mathrm{EC}_{50}$.

8Br-cGMP, statistically significant CRCs shift to the left was observed, in relation to the control (Figure 2, Table 2).

Comparison of CRCs drawn for AVP after I/R and in the presence of $8 \mathrm{Br}$-cGMP demonstrates that the strongest arterial contractile reaction occurs after 90 minutes of reperfusion with no $8 \mathrm{Br}$-cGMP. The lowest reaction is found for postischemia arteries with $8 \mathrm{Br}$-cGMP (Figure 3 ).

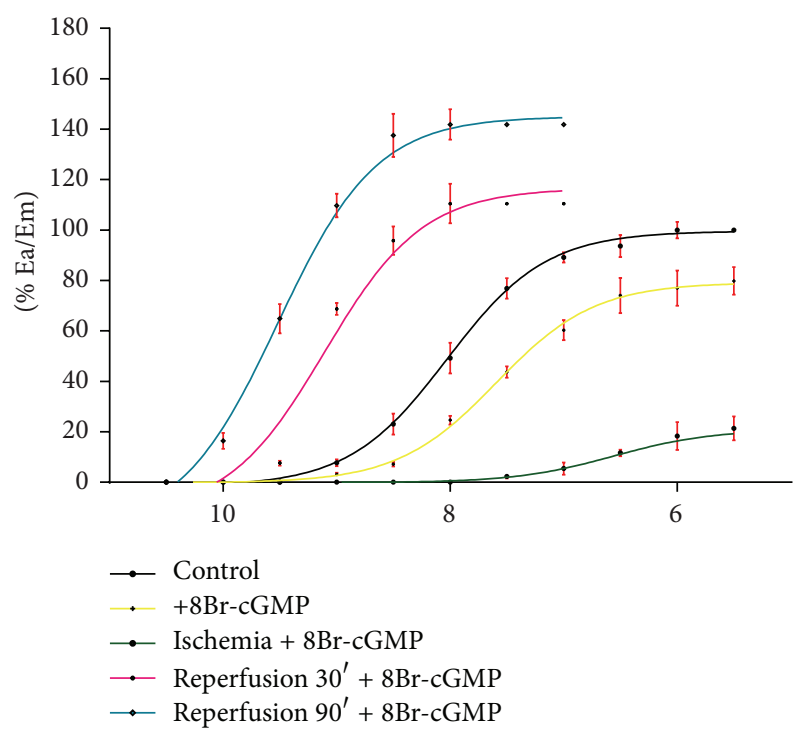

Figure 2: The effect (\% Ea/Em) of $8 \mathrm{Br}-\mathrm{cGMP}$ on CRCs for AVP in control, ischemia $30^{\prime}$, and reperfusion $30^{\prime}$ and $90^{\prime}$ conditions.

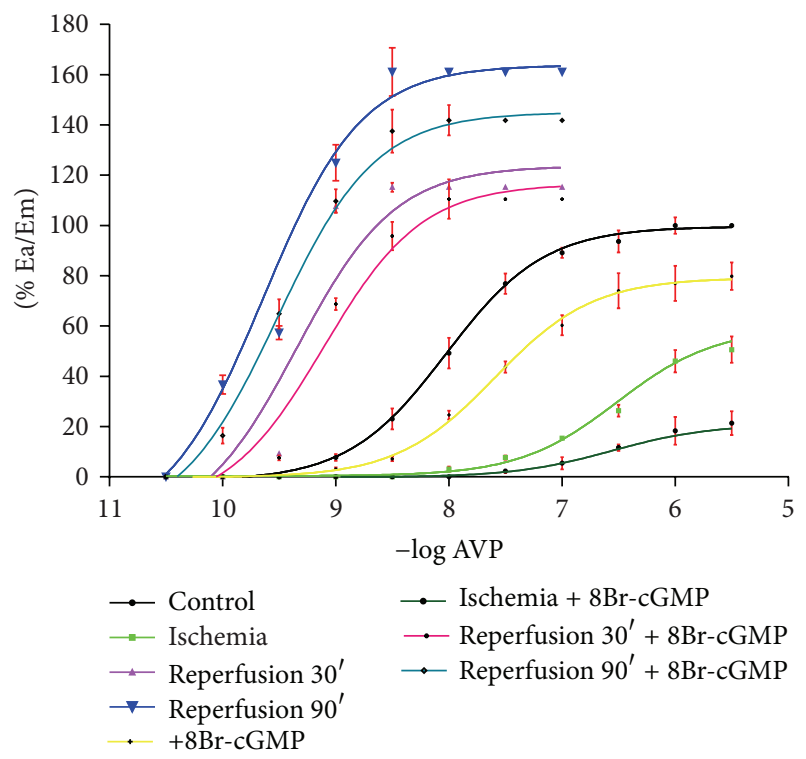

Figure 3: The effect (\% Ea/Em) of ischemia $30^{\prime}$, reperfusion $30^{\prime}$ and $90^{\prime}$, and $8 \mathrm{Br}-\mathrm{cGMP}$ added in those conditions on CRCs for AVP.

Control arteries, after 90 minutes of reperfusion, after 30 minutes of reperfusion, and after ischemia with $8 \mathrm{Br}$ cGMP, present their CRCs shifted to the right in relation to corresponding curves with no reagent added (Figure 3 ).

\section{Discussion}

Surgical procedures, including coronary artery bypass grafting or transplantations, are associated with temporary ischemia followed by reperfusion, which may lead to a local contraction of smooth muscles $[28,29]$. Increased muscular contractility developing after I/R causes an extensive increase of calcium ion level and damage of endothelial cells and 
smooth muscles. That may disturb the equilibrium between factors causing constriction and relaxation of vessels and cause a complete elimination of blood flow [30, 31].

$\mathrm{VP}$ is one of the best known vasoconstrictors. VP is responsible for osmosis and cardiovascular homeostasis. In normal conditions, the level of VP ranges between 1 and $5 \mathrm{pg} / \mathrm{mL}$. Numerous studies have been realised involving external administration of VP and leading to a significant rise of its concentration in the organism. Yang et al. [21] demonstrated, after their predecessors $[32,33]$, that endogenous VP causes a decrease of body temperature in rodents. Moreover, the receptor V1a, participating in that process [32], is the same receptor that is responsible for vasoconstrictive role of VP. It is interesting, as triggering an inflammatory reaction is one of the elements of the reperfusion cascade. Antipyretic properties of VP may influence the reaction of arteries after reperfusion, avoiding subsequent stages of the cascade. However, its excessively high level may be associated with a different effect, as intravenously and intracerebrally administered VP leads to hypothermia [21].

Studies on the role of AVP in brain injuries are also on their way. Experiments carried out by SzmydyngerChodobska et al. demonstrated a pathological role of VP in brain injuries, including amplification of the posttraumatic production of proinflammatory mediators [23]. Manaenko et al. demonstrated that inhibition of the receptor V1a reduced brain injury and oedema [20].

Martikainen et al. [34] in their studies on swine model verified the role of VP after cerebral death with small intestine transplantation in patients with the short bowel syndrome. Cerebral death leads to increase of intracranial pressure, which gradually reduces blood flow to the brain. Cerebral ischemia causes activation of the sympathetic nervous system, which leads to narrowing of vessels and increased arterial blood pressure. However, in a short period of time the effect disappears, with resulting hypotension and hypoperfusion, which forces surgeons to apply vasoconstrictors $[18,34]$. Despite the fact that vasopressin has reduced blood pressure, the systemic and enteral blood flow was endangered, and that circulation was of a particular interest considering the organ collected for transplantation. With VP, insufficient amounts of oxygen were supplied to tissues. That effect was not observed with other vasoconstrictors [34]. However, Rosendale et al. demonstrated a positive effect of pharmacological agents, including VP, on increased number of organs (heart) for transplantations [35].

In present experiments, AVP, a nonselective agonist of $\mathrm{VP}$ receptors type $\mathrm{Vla}$, present in vascular smooth muscle cells, was used. It is a metabotropic receptor, activation of which leads to contraction of blood vessels as a consequence of inflow of calcium ions to the cytoplasm.

The $\mathrm{pEC}_{50}$ value of 7.987, determined for AVP in this study, is comparable to other studies in which arterial smooth muscle cells contraction was triggered with AVP (7.76 \pm 0.14$)$. The value is close to the one determined in studies on phenylephrine-triggered contraction of smooth muscle cells $\left(\mathrm{pEC}_{50}=7.13 \pm 0.06\right)$. Phenylephrine is a relatively selective agonist of the adrenergic receptor type $\alpha 1$. Similarly as in the case of AVP, contraction of the smooth muscle cells occurs with inflow of calcium ions to cytoplasm [36, 37]. Both receptors are activated in course of therapy of septic shock by administration of noradrenalin and dopamine ( $\alpha$-adrenergic receptor) followed by desmopressin (V1a) [36-38].

The effect of AVP on contraction of vascular smooth muscle cells was studied on arteries with preserved endothelium, being an integral part of the vascular wall, and regulating function of the vessel through release of various substances modulating tension of smooth muscle cells. If a vessel functions normally, endothelium reduces reactivity of the artery through release of prostanoids and NO. NO has a strong relaxing effect on the vessel. However, if endothelium is damaged, the vessel becomes more susceptible to stimulation with constrictors. A similar effect may be achieved by inhibition of NO synthase activity $[39,40]$.

$8 \mathrm{Br}-\mathrm{cGMP}$ is a cGMP analogue, that is hardly hydrolysed and may easily penetrate cells. Its action is analogous to the action of NO. Therefore, the mechanism of $8 \mathrm{Br}-\mathrm{cGMP}$ corresponds to cGMP-dependent reactions occurring as a result of synthesis of NO. That leads to cellular hyporeactivity $[9,41]$. Studies demonstrated a significant effect of $8 \mathrm{Br}-\mathrm{cGMP}$ on arterial reactions to AVP. Values for the control after addition of the reagent $\left(\mathrm{pEC}_{50}=7.587\right)$ are slightly higher than reported from another study for the same concentration $\left(\mathrm{pEC}_{50}=6.94 \pm 0.12\right)[12,23]$, but both studies indicate the relaxing role of $8 \mathrm{Br}-\mathrm{cGMP}$ in case of artery stimulation with AVP. Also the shape of CRCs compared to a common control is observed.

Similarly to other vasoconstrictors, ischemia caused a significant reduction of arterial reactions, demonstrating statistical significance at all levels of concentration for which the arterial reaction was observed. Addition of 8Br-cGMP reduced arterial contractility even more, exhibiting statistical significance for the last four concentrations of the administered AVP. NO is the best known substance acting through cGMP [42]. Reaction of cyclic nucleotides, including cAMP and cGMP, is converse to the amount of calcium ions in vascular smooth muscle cells. With decreased amount of $\left[\mathrm{Ca}^{2+}\right]$ and with reduced smooth muscle cells susceptibility to those ions, nucleotide vasodilating action is increased [9].

A similar arterial reaction was demonstrated for other vasoconstrictors, including angiotensin II (ANG II) after 30 minutes of ischemia [39]. After that time, the $\mathrm{EC}_{50}$ value for arteries under the effect of AVP is $3.355 \times 10^{-6}$ and for ANG II is $2.89 \times 10^{-7}$. Although those values are not identical, the obtained concentration-result curves indicate similar action of both vasoconstrictors.

This study aimed at the effect of AVP on reaction of the smooth muscle cells under reperfusion conditions. Reperfusion lasting 90 minutes reached the highest ratio (\% $\mathrm{Ea} / \mathrm{Em}=168.60)$. The $\mathrm{EC}_{50}$ value was $2.546 \times 10^{-9}$. The result is comparable to those for ANG II $\left(2.17 \times 10^{-9}\right)$. That indicates similarity of both vasoconstrictors under conditions of ischemia and reperfusion.

Similarly to the reperfusion lasting for 90 minutes, the 30-minute reperfusion triggered a more pronounced arterial reaction to AVP than the control. However, the reaction was less pronounced than the reaction of arteries after a 90minute reperfusion. The shape of curves resembles curves 
drawn for ischemia and 30- and 90-minute reperfusion in relation to the control for ANG II in the analogous study.

The study demonstrated that CRCs for AVP in the presence of $8 \mathrm{Br}-\mathrm{cGMP}$ are shifted to the right, with a simultaneous reduction of the maximum effect. Similarly to other studies, the presented results indicate unaltered effect of the compound on blood vessels. 8Br-cGMP (and consequently also NO) inhibits overreactivity of blood vessels to AVP triggered by reperfusion and reduced reaction of arteries for the control and ischemia [39]. Similarity of the reaction of the smooth muscle cells stimulated by AVP to the reaction of arteries under the influence of ANG II in a vessel with preserved endothelium allows presumption, that a similar effect would be observed for endothelium-depleted arteries. Contractive hyperreactivity after reperfusion achieved in the experiment, along with literature data, indicates that it is endothelium-independent. However, the relaxing effect of NO is observed $[9,31]$. Excessive contraction of the artery leads to damage of its smooth muscle cells and endothelium, with longer reperfusion that leads to increased contraction.

\section{Conclusions}

Ischemia and reperfusion modulate arterial constriction triggered by AVP. The effect of $8 \mathrm{Br}-\mathrm{cGMP}$ on reactions stimulated by AVP after ischemia and reperfusion indicates participation of the signalling pathway associated with NO and cGMP in regulation of the tension of the smooth muscle cells triggered by the vasoconstrictor.

\section{Abbreviations}

ADH: Antidiuretic hormone

ANG II: Angiotensin II

AVP: Arginine vasopressin

CG: Guanylate cyclase

I/R: Ischemia/reperfusion

NO: $\quad$ Nitric oxide

ROS: $\quad$ Reactive oxygen species

VP: Vasopressin.

\section{Competing Interests}

The authors declare no competing interests.

\section{References}

[1] J. D. Palombo, G. L. Blackburn, and R. A. Forse, "Endothelial cell factors and response to injury," Surgery Gynecology \& Obstetrics, vol. 173, no. 6, pp. 505-518, 1991.

[2] R. M. J. Palmer, A. G. Ferrige, and S. Moncada, "Nitric oxide release accounts for the biological activity of endotheliumderived relaxing factor," Nature, vol. 327, no. 6122, pp. 524-526, 1987.

[3] H. K. Diep, E. J. Vigmond, S. S. Segal, and D. G. Welsh, "Defining electrical communication in skeletal muscle resistance arteries: a computational approach," Journal of Physiology, vol. 568, no. 1, pp. 267-281, 2005.
[4] E. L. Rowe and N. A. White, "Reperfusion injury in the equine intestine," Clinical Techniques in Equine Practice, vol. 1, no. 3, pp. 148-162, 2002.

[5] R. M. Tribe, M. L. Borin, and M. P. Blaustein, "Functionally and spatially distinct $\mathrm{Ca}^{2+}$ stores are revealed in cultured vascular smooth muscle cells," Proceedings of the National Academy of Sciences of the United States of America, vol. 91, no. 13, pp. 59085912, 1994.

[6] K. E. Kamm and J. T. Stull, "Dedicated myosin light chain kinases with diverse cellular functions," Journal of Biological Chemistry, vol. 276, no. 7, pp. 4527-4530, 2001.

[7] R. M. Moore, W. W. Muir, and D. N. Granger, "Mechanisms of gastrointestinal ischemia-reperfusion injury and potential therapeutic interventions: a review and its implications in the horse," Journal of Veterinary Internal Medicine, vol. 9, no. 3, pp. 115-132, 1995.

[8] M. Slupski, L. Szadujkis-Szadurski, G. Grześk et al., "Guanylate cyclase activators influence reactivity of human mesenteric superior arteries retrieved and preserved in the same conditions as transplanted kidneys," Transplantation Proceedings, vol. 39, no. 5, pp. 1350-1353, 2007.

[9] K. Szadujkis-Szadurska, G. Grzesk, L. Szadujkis-Szadurski, M. Gajdus, and G. Matusiak, "Role of nitric oxide and cGMP in the modulation of vascular contraction induced by angiotensin II and Bay K8644 during ischemia/reperfusion," Experimental and Therapeutic Medicine, vol. 5, no. 2, pp. 616-620, 2013.

[10] R. M. Moore, J. Hardy, and W. W. Muir, "Mural blood flow distribution in the large colon of horses during low-flow ischemia and reperfusion," American Journal of Veterinary Research, vol. 56, no. 6, pp. 812-818, 1995.

[11] D. N. Granger, J. N. Benoit, M. Suzuki, and M. B. Grisham, "Leukocyte adherence to venular endothelium during ischemiareperfusion," American Journal of Physiology-Gastrointestinal and Liver Physiology, vol. 257, no. 5, pp. G683-G688, 1989.

[12] K. Szadujkis-Szadurska, G. Grzesk, L. Szadujkis-Szadurski, M. Gajdus, B. Malinowski, and M. Wicinski, "Role of endothelium, acetylocholine and calcium ions in Bay $\mathrm{K} 8644$ - and $\mathrm{KCl}$ induced contraction," Molecular Medicine Reports, vol. 8, no. 3, pp. 914-918, 2013.

[13] G. Oliver and E. A. Schäfer, "On the physiological action of extracts of pituitary body and certain other glandular organs," The Journal of Physiology, vol. 18, no. 3, pp. 277-279, 1895.

[14] P. R. Kalra, S. D. Anker, and A. J. S. Coats, "Water and sodium regulation in chronic heart failure: the role of natriuretic peptides and vasopressin," Cardiovascular Research, vol. 51, no. 3, pp. 495-509, 2001.

[15] V. Krejci, L. B. Hiltebrand, S. M. Jakob, J. Takala, and G. H. Sigurdsson, "Vasopressin in septic shock: effects on pancreatic, renal, and hepatic blood flow," Critical Care, vol. 11, no. 6, article R129, 2007.

[16] E. Popp, P. Vogel, P. Teschendorf, and B. W. Böttiger, "Vasopressors are essential during cardiopulmonary resuscitation in rats: is vasopressin superior to adrenaline?" Resuscitation, vol. 72, no. 1, pp. 137-144, 2007.

[17] B. Hauser, P. Asfar, E. Calzia, R. Laporte, M. Georgieff, and P. Radermacher, "Vasopressin in vasodilatory shock: is the heart in danger?" Critical Care, vol. 12, no. 2, article 132, 2008.

[18] S. Müller, O.-J. How, S. E. Hermansen, T. A. Stenberg, G. Sager, and T. Myrmel, "Vasopressin impairs brain, heart and kidney perfusion: an experimental study in pigs after transient myocardial ischemia," Critical Care, vol. 12, no. 1, article R20, 2008. 
[19] P. M. Park, S. S. Gao, S. A. Cha, B. H. Park, and S. H. Kim, "Cardioprotective effects of angiotensin III against ischemic injury via the AT2 receptor and KATP channels," Physiological Reports, vol. 1, no. 6, Article ID e00151, 2013.

[20] A. Manaenko, N. Fathali, N. H. Khatibi et al., "Argininevasopressin $\mathrm{V}_{\text {la }}$ receptor inhibition improves neurologic outcomes following an intracerebral hemorrhagic brain injury," Neurochemistry International, vol. 58, no. 4, pp. 542-548, 2011.

[21] Y.-L. Yang, Z.-L. Shen, Q. Zou, Y. Tang, and T. Huang, "Physostigmine-induced hypothermic response in rats and its relationship with endogenous arginine vasopressin," Life Sciences, vol. 85, no. 15-16, pp. 586-591, 2009.

[22] E. M. Briley, S. J. Lolait, J. Axelrod, and C. C. Felder, "The cloned vasopressin V1a receptor stimulates phospholipase A2, phospholipase $\mathrm{C}$, and phospholipase $\mathrm{D}$ through activation of receptor-operated calcium channels," Neuropeptides, vol. 27, no. 1, pp. 63-74, 1994.

[23] J. Szmydynger-Chodobska, B. J. Zink, and A. Chodobski, "Multiple sites of vasopressin synthesis in the injured brain," Journal of Cerebral Blood Flow and Metabolism, vol. 31, no. 1, pp. 47-51, 2011.

[24] C. L. Holmes, D. W. Landry, and J. T. Granton, "Science review: vasopressin and the cardiovascular system part 1-receptor physiology," Critical Care, vol. 7, no. 6, pp. 427-434, 2003.

[25] J. M. van Rossum, "Cumulative dose-response curves. II. Technique for the making of dose-response curves in isolated organs and the evaluation of drug parameters," Archives Internationales de Pharmacodynamie et de Thérapie, vol. 143, pp. 299-330, 1963.

[26] G. Grześk and L. Szadujkis-Szadurski, "Pharmacometric analysis of $\alpha 1$-adrenoceptor function in rat tail artery pretreated with lipopolysaccharides," Polish Journal of Pharmacology, vol. 53, no. 6, pp. 605-613, 2001.

[27] G. Grzesk and L. Szadujkis-Szadurski, "Physiological antagonism of angiotensin II and lipopolysaccharides in early endotoxemia: pharmacometric analysis," Polish Journal of Pharmacology, vol. 55, pp. 753-762, 2003.

[28] A. Szabo and U. Heemann, "Ischemia reperfusion injury and chronic allograft rejection," Transplantation Proceedings, vol. 30, no. 8, pp. 4281-4284, 1998.

[29] C. S. H. Ng, S. Wan, and A. P. C. Yim, "Pulmonary ischaemiareperfusion injury: role of apoptosis," European Respiratory Journal, vol. 25, no. 2, pp. 356-363, 2005.

[30] K. Hashimoto, P. J. Pearson, H. V. Schaff, and R. Cartier, "Endothelial cell dysfunction after ischemic arrest and reperfusion: a possible mechanism of myocardial injury during reflow," Journal of Thoracic and Cardiovascular Surgery, vol. 102, no. 5, pp. 688-694, 1991.

[31] R. J. Dignan, C. M. Dyke, A. S. Abd-Elfattah et al., "Coronary artery endothelial cell and smooth muscle dysfunction after global myocardial ischemia," The Annals of Thoracic Surgery, vol. 53, no. 2, pp. 311-317, 1992.

[32] Q. J. Pittman and M. F. Wilkinson, "Central arginine vasopressin and endogenous antipyresis," Canadian Journal of Physiology and Pharmacology, vol. 70, no. 5, pp. 786-790, 1992.

[33] C. A. Richmond, "The role of arginine vasopressin in thermoregulation during fever," The Journal of Neuroscience Nursing, vol. 35, no. 5, pp. 281-286, 2003.

[34] T. J. Martikainen, J. Kurola, V. Kärjä, I. Parviainen, and E. Ruokonen, "Vasopressor agents after experimental brain death: effects of dopamine and vasopressin on vitality of the small gut," Transplantation Proceedings, vol. 42, no. 7, pp. 2449-2456, 2010.
[35] J. D. Rosendale, H. M. Kauffman, M. A. McBride et al., "Aggressive pharmacologic donor management results in more transplanted organs," Transplantation, vol. 75, no. 4, pp. 482487, 2003.

[36] G. Grześk, M. Wiciński, B. Malinowski et al., "Calcium blockers inhibit cyclosporine A-induced hyperreactivity of vascular smooth muscle cells," Molecular Medicine Reports, vol. 5, no. 6, pp. 1469-1474, 2012.

[37] G. Grzesk, B. Malinowski, E. Grzesk et al., "Direct regulation of vascular smooth muscle contraction by mastoparan-7," Biomedical Reports, vol. 2, pp. 34-38, 2014.

[38] L. G. Hall, L. J. Oyen, C. B. Taner et al., "Fixed-dose vasopressin compared with titrated dopamine and norepinephrine as initial vasopressor therapy for septic shock," Pharmacotherapy, vol. 24, no. 8, pp. 1002-1012, 2004.

[39] K. Szadujkis-Szadurska, G. Grzesk, L. Szadujkis-Szadurski, M. Gajdus, and G. Matusiak, "Role of acetylcholine and calcium ions in three vascular contraction models: angiotensin II, phenylephrine and caffeine," Experimental and Therapeutic Medicine, vol. 4, no. 2, pp. 329-333, 2012.

[40] G. Yetik-Anacak and J. D. Catravas, "Nitric oxide and the endothelium: history and impact on cardiovascular disease," Vascular Pharmacology, vol. 45, no. 5, pp. 268-276, 2006.

[41] J. Xu and L. Liu, "The role of calcium desensitization in vascular hyporeactivity and its regulation after hemorrhagic shock in the rat," Shock, vol. 23, no. 6, pp. 576-581, 2005.

[42] R. F. Furchgott and J. V. Zawadzki, "The obligatory role of endothelial cells in the relaxation of arterial smooth muscle by acetylcholine," Nature, vol. 288, no. 5789, pp. 373-376, 1980. 

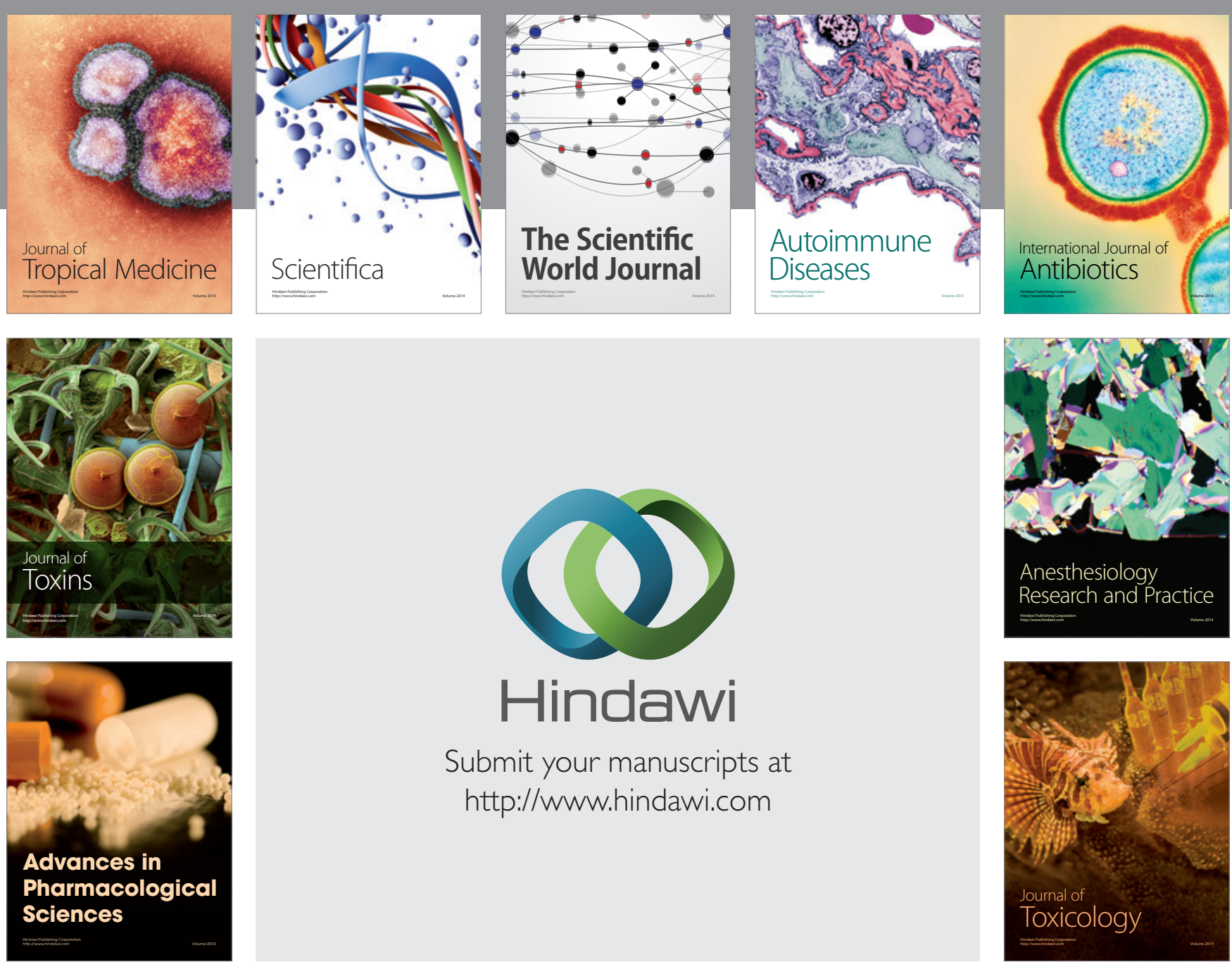

\section{Hindawi}

Submit your manuscripts at

http://www.hindawi.com
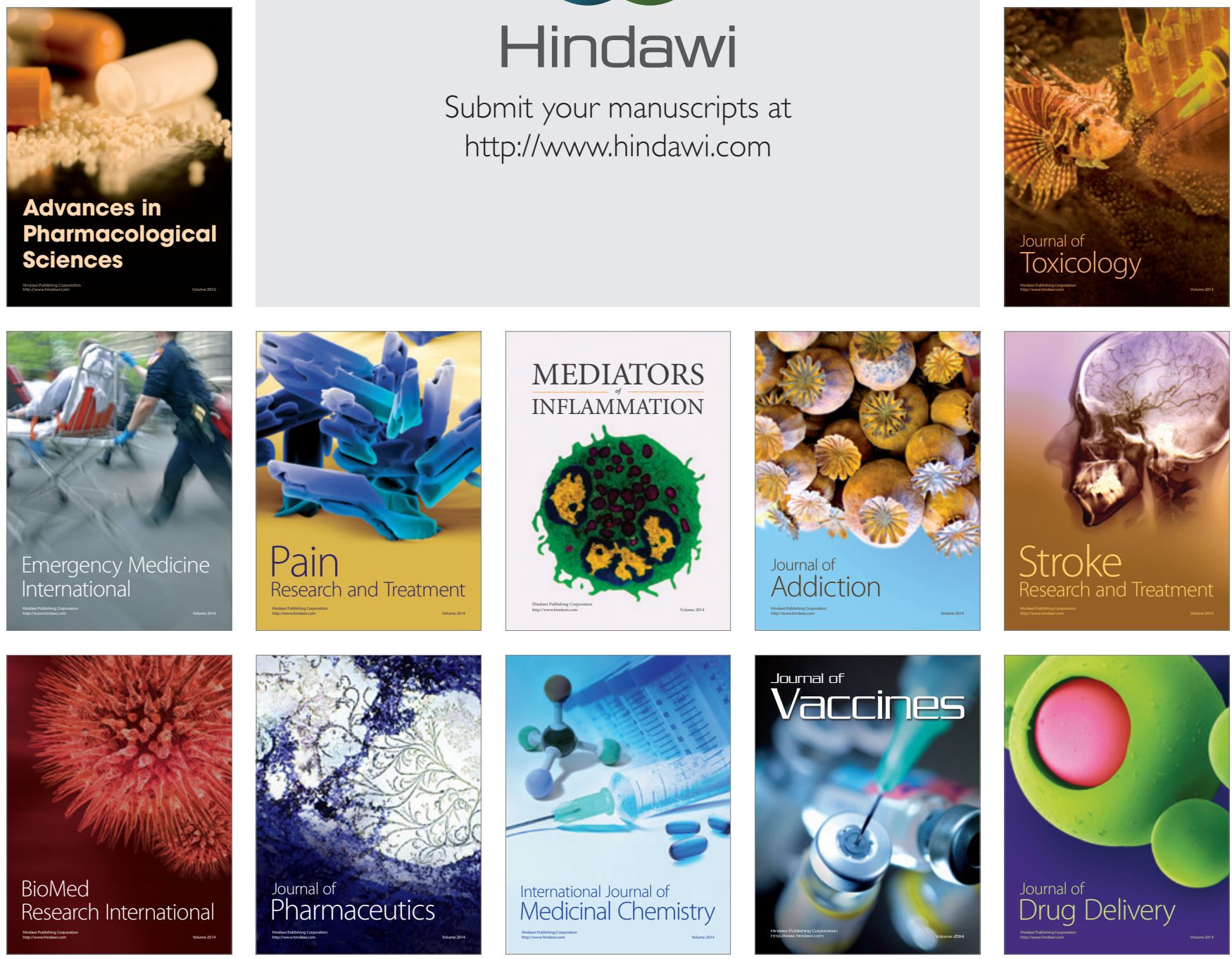